\title{
Sulfur isotopic record associated with the late Cambrian Steptoean Positive Carbon Isotope Excursion (SPICE) from South China
}

\author{
Jing HuANG ${ }^{1}$, LiAnJun FenG ${ }^{2}$, XUELEI CHU ${ }^{2}$
}

${ }^{1}$ Center of Deep Sea Research, Institute of Oceanography, Chinese Academy of Sciences, Qingdao 266071, China ${ }^{2}$ Institute of Geology and Geophysics, Key Laboratory for Mineral Resources, Chinese Academy of Sciences, Beijing 100029, China

The Steptoean Positive Carbon Isotope Excursion (SPICE) show a parallel sulfur isotopic positive shift in general, but with significant heterogeneity in the peak times and heights of the sulfur isotope excursions for which the cause remains elusive. Here, we report carbon and sulfur isotopes in the late Cambrian carbonate from the Wangcun section, South China. The carbon isotopes in both carbonate $\left(\delta^{13} \mathrm{C}_{\text {carb}}\right)$ and organic carbon $\left(\delta^{13} \mathrm{C}_{\text {org }}\right)$ show characteristic positive excursions within the Paibian Stage, but the sulfur isotopes in carbonate-associated sulfate $\left(\delta^{34} \mathrm{~S}_{\mathrm{CAS}}\right)$ and pyrite $\left(\delta^{34} \mathrm{~S}_{\mathrm{py}}\right)$ each show two potential positive peaks (PS1 and PS2). The S-isotopic fractionation (i.e., $\Delta^{34} \mathrm{~S}_{\text {CAS-py }}$ ) show a decrease and a subsequent increase predating the $\delta^{13} \mathrm{Ccarb}$ peak, and the maximum $\Delta^{34} \mathrm{~S}_{\text {CAS-py }}$ of up to $+51.1 \%$ is close to the peak of $\delta^{13} \mathrm{C}_{\text {carb. }}$. Our sulfur cycling simulations show that the $\Delta^{34} \mathrm{~S}_{\text {CAS-py }}$ changes played an important role in the SPICE sulfur isotope records, although it is still ambiguous what caused the wide variations of $\Delta^{34} \mathrm{~S}_{\mathrm{CAS} \text {-py }}$ in the context of low-sulfate conditions during the SPICE. The modelling results indicate that (1) enhanced pyrite burial would result in a primary positive $\delta^{34} \mathrm{~S}_{\mathrm{CAS}}$ peak (PS1) predating the $\delta^{13} \mathrm{C}_{\text {carb }}$ peak, and its peak time and peak height may be controlled by various factors (e.g., the initial sulfate residence time, magnification of pyrite burial, changes of sulfate input flux, changing rate of $\Delta^{34} S$ ); (2) rapid $\Delta^{34} S_{\text {CAS-py }}$ increase combined with enhanced pyrite burial would yield an additional positive $\delta^{34} S_{\text {CAS }}$ peak (PS2), which always emerged near the termination of the enhanced pyrite burial (close to the $\delta^{13} \mathrm{C}_{\text {carb }}$ peak); (3) PS1 might be smoothed under certain conditions (e.g., large initial sulfate residence time or small magnification of pyrite burial), and only PS2 can be observed. These findings can be well applied to explain the heterogeneity in the global SPICE sulfur isotopic records. 